\title{
On a new chloride and oxide of chromium
}

\section{M.Eug. Peligot}

To cite this article: M.Eug. Peligot (1844) On a new chloride and oxide of chromium, Philosophical Magazine Series 3, 25:168, 484-486, DOI: 10.1080/14786444408646088

To link to this article: http://dx.doi.org/10.1080/14786444408646088

曲 Published online: 30 Apr 2009.

Submit your article to this journal 준

Џ Article views: 2

Q View related articles $₫$ 
a little water, or what is still better, in a weakly alkaline liquor, and crystallized; without this precaution, the salt which crystallizes is partly decomposed, retains always a certain quantity of acid aluminate, and when subjected to aralysis it gives more alumina than is indicated by theory.

When water is expelled from aluminate of potash by heat, it appears to be partially decomposed, for when treated with water a part of the salt is found to be insoluble. Other salts formed by metallic acids undergo similar decomposition by heat.

Aluminate of soda is formed in the same way as aluminate of potash, but crystallizes less readily. Other aluminates are all insoluble ; they are formed by double decomposition, and possess but little interest.

\section{Iron and Ferric Acid.}

M. Fremy remarks, that protoxide of iron is soluble in ammonia, and forms a combination which has not hitherto been examined; but this oxide does not combine with the fixed alkalies; when a solution of a protosalt of iron is precipitated by a concentrated solution of potash, and the liquor is boiled, it disengages a considerable quantity of hydrogen; the protoxide of iron is then converted into black oxide; the experiments of MM. Liebig and Wöhler have shown the facility with which protoxide of iron decomposes water.

Peroxide of iron does not appear to combine with the alkalies in definite proportion. When a persalt of iron is precipitated by excess of potash, the hydrate of the peroxide always retains a certain quantity of potash; the proportion of alkali combined is variable, and never occurs in simple relation to the oxide of iron.

If however the two oxides of iron do not combine directly with the alkalies, the author observes, that he has found by superoxidizing the sesquioxide of iron that it was converted into a compound which has all the properties of an acid, and to which he has given the name of ferric acid.

Thus then, iron, like manganese, chromium, tin, and several other metals, forms at first energetic oxides, and by superoxidizement yields a metallic acid.-Ann. de Ch. et de Phys., Novembre 1844.

\section{ON A NEW CHLORIDE AND OXIDE OF CHROMIUM.}

BY M. EUG. PELIGOT.

It is well known that when a current of chlorine is passed over a mixture of oxide of chromium and charcoal, that a chloride is obtained which sublimes in fine violet-coloured scales; this compound corresponds to the sesquioxide of chromium, $\mathrm{Cr}^{2} \mathrm{O}^{3}$; its composition M. Peligot states from recent experiments to be represented by $\mathrm{Cr}^{2}$ Cls.

This is not however the only chloride formed in this operation; it is preceded by another chloride which appears to have escaped the notice of chemists, and which is in very white silky crystals, usually mixed with charcoal and oxide of chromium; these crystals become green immediately on exposure to the air, and quickly become a green solution; they absorb both oxygen and moisture at the same time 
from the atmosphere. The analyses which the author has performed of this chloride leave no doubt as to its nature; it is composed of one equivalent each of metal and chloride, $\mathrm{CrCl}$. It consequently corresponds to a degree of oxidation of chromium as yet unknown, CrO.

This same substance is formed when a current of hydrogen is passed over green chloride of chromium heated to low redness; hydrochloric acid is evolved, and a white crystalline mass remains; when operating at a higher temperature, this mass fuses, and on cooling presents a fibrous texture.

Protochloride of chromium prepared by either of these methods has the following properties :-it dissolves immediately in water; if the water is aërated, and if air be present during solution, the liquor has a green colour, but it is blue when the influence of oxygen is prevented. M. Peligot states that he is acquainted with no substance which is more rapidly altered than this by the contact of oxygen ; so that in order to ascertain its properties it is necessary to operate with water deprived of air by ebullition, and in an atmosphere of carbonic acid gas.

The green solution resulting from the action of air and water on the protochloride of chromium, possesses the singular property of dissolving a considerable quantity of the violet chloride of chromium, with the disengagement of much heat; this latter body, when pure, is entirely insoluble in water and in acids; this property of the white chloride, which accompanies the violet chloride when prepared in the usual way, has thrown much uncertainty on the true characters of this latter body, which some authors consider as very soluble in water, and as producing a green solution, while others with reason dispute its solubility.

When protochloride of chromium has been prepared with the sesquichloride and hydrogen, it dissolves in water with the evolution of hydrogen; this decomposition of water, which is not considerable, seems to indicate the existence of a subchloride, which would result, like the subchloride of uranium, from the long-continued action of the hydrogen on the protochloride.

The blue solution of protochloride of chromium gives with potash a brown precipitate, which is probably a hydrate of the protoxide, corresponding to the chloride; ammonia gives a similar precipitate; an excess of ammonia gives a blue solution, which by exposure to the air becomes violet, and eventually red; monosulphuret of potassium precipitates the protochloride of chromium black.

On pouring a solution of acetate of potash or soda into the blue solution of chloride of chromium, small red transparent crystals are immediately formed, which rapidly collect at the bottom of the vessel. These crystals are spoiled by a few seconds' exposure to the air ; it is however possible to obtain them in a pure state, by a process hereafter to be described, and when dry they have the aspect of protoxide of copper.

These crystals are the acetate of protoxide of chrominm, the composition of which, taking the mean of four analyses which differed but little, is represented by the formula $\mathrm{C}^{4} \mathrm{H}^{3} \mathrm{O}^{3}, \mathrm{CrO}, \mathrm{HO}$. A double sulphate of potash and protoxide of chromium gave the following as 
the formula of its composition, $\mathrm{SO}^{3} \mathrm{KO}+\mathrm{SO}^{3}, \mathrm{CrO}+6 \mathrm{HO}$. The author has not yet determined the composition of the protoxide of chromium, but is engaged in ascertaining it.-Journ. de Pharm. et de Ch., Nov. 1844.

ACETATE OF IRON AS A REMEDY FOR ARSENICAL PREPARATIONS.

The hydrated peroxide of iron is of admitted efficacy in cases of poisoning with uncombined arsenious or arsenic acid; but according to the experiments of Duflos, it is quite ineffectual when these acids are combined with bases, as for example, Fowler's solution, or arsenite of potash, or arseniate of potash, which last is frequently employed in calico-printing, and is consequently easily procured.

In the uncertainty in which the practitioner may be placed as to whether the arsenical poison be free or combined, it is very important to administer the oxide of iron in such a form as to produce a favourable result: to this end it is convenient to employ the peracetate of iron.

This compuund may be prepared by adding to the hydrated peroxide of iron obtained from the decomposition of four parts of liquid perchloride of iron, three parts of acetic acid of density 1.06, and sufficient water to make up 16 parts.

This liquid, which is a solution of peracetate of iron with excess of base, precipitates arsenious and arsenic acid from all their solutions, either free, or combined with any base; $\mathbf{5 0 0}$ grains of it are sufficient to decompose 1880 grains of Fowler's solution.

This result demonstrates that liquid peracetate of iron merits preference in cases of poisoning by arsenical compounds. It should be remembered that its power is more rapid in proportion as it is more diluted with water; besides which, large dilution prevents all irritating action of the acetic acid set free.-Journ. de Ch. Méd., Novembre 1844.

[The mode of preparing the above compound is not very clearly stated, for the strength of the liquid perchloride of iron is not given. It may be presumed that peracetate of iron mixed with peroxide is to be employed ; the degree of excess of the latter is of little consequence, and the strength of the peracetate is limited by the employment of four parts of acetic acid of 1.06 made up to 16 parts with water, and this, it appears, is to be largely diluted before exhibited. -EDIT.]

ON A NEW CHARACTER OF THE SALTS OF LIME AND MAGNESIA.

M. Marchand remarks, that all treatises on chemistry agree in stating that the salts of lime and magnesia are not precipitated by the ferrocyanide of potassium. The ferrocyanides of calcium and magnesium being very soluble in water, also induced the belief that the characters stated by authors were correct; this however is not the case, for when ferrocyanide of potassium is added to even weak solutions of salts of lime or magnesia, an abundant precipitate of a slightly yellowish-white colour soon begins to deposit, and it adheres strongly to the sides of the vessel. The only precaution to be taken in producing the effect, is to take care that the solutions are per- 